\section{Na teia invisível \\ do som: por uma geofonia da comunicação}

Obs.: Há oito anos vimos tentando propor uma forma de inteirar conhecimentos em diversos campos, a fim de aproximar experiências recentes que auxiliem uma compreensão mais adequada do som e mesmo da música como uma forma de comunicação importante na era tecnológica. $\mathrm{O}$ texto é um exercício inicial de reflexão sobre as teias invisíveis do som do mundo e sobre como tecemos com ele (muitas vezes sem perceber) inúmeras relações. Chama-se a atenção não só para a amplitude do tema mas principalmente para a geofonia, disciplina que ajudaria a abarcar ampla gama de fenômenos sonoros hoje estudados isoladamente pela música, pela bioacústica e pela engenharia acústica, entre outras. $\mathrm{O}$ objetivo é alcançar uma compreensão mais adequada da forma pela qual percebemos auditivamente o mundo à nossa volta, para não ignorarmos o que silenciosamente dele nos tem passado despercebido.

\section{Marta Catunda}

Mestre em Ciências da Comunicação - ECA/USP, Doutoranda em Educação e Meio-ambiente - UFMT
"A tenacidade e a clarividência são espectadores privilegiados desse jogo inumano em que o absurdo, a esperança e a morte intercambiam suas réplicas."

(Albert Camus, o Mito de Sisifo, 1951)

A EFICIÊNCIA DO HOMEM em alterar seu ambiente ao longo dos tempos se deve, em grande parte, à sua extraordinária capacidade de elaborar artefatos e ferramentas. De modo semelhante, as aranhas modificam seu ambiente utilizando fios de seda que possibilitam alavancar sua evolução: a teia. Enquanto o homem teve, na via cultural, a principal aliada do sucesso, as aranhas, ao longo da evolução, percorreram apenas a via genética. Do ponto de vista da engenharia, guardadas as devidas proporções, a teia na aranha desenvolveu-se ao longo de milhões de anos, a partir da fisiologia de seus "laboratórios" (glândulas situadas na extremidade posterior do abdome), que produzem vários tipos de seda. As "teias" humanas desenvolveram-se nos últimos 150 anos, a partir do engenho de tecnologia laboriosa (das linhas de comunicação até as "redes"), que produzem inúmeras formas de comunicação. A aranha depende das condições fisiológicas e o homem das condições tecnológicas. Em ambos, o intrincamento das "teias" reflete padrões complexos de comportamento social, formando uma unidade (aranha-teia/homem-rede) e sendo também extensão do aparato sensorial . A evolução no homem não é alavancada tão somente pela via genética, mas, principalmente, pela conduta técnica e cultural, embora, graças à técnica e às tecnologias atuais, seja possível a manipulação do próprio código da vida: o DNA.

Virilio (1996) observa que a entrada em cena da realidade virtual coloca uma questão fundamental: a redefinição da matéria. No conceito atual de matéria, um novo componente acrescenta-se à massa e à energia: a informação. Isso é de algum modo inapreensível, pelo pouco que conhecemos da informática. Sem esse conheci- 
mento, ou do modo precário como a entendemos, não conseguimos raciocinar perfeitamente algo como informação, passando a fazer parte da física. Ou seja, é necessário entender que a forma não é apenas geométrica, volumétrica, energética, mas também informática.

O som, como parte da física, como a informação, é invisível, se manifesta por efeitos. A Física atual demonstra que tudo no universo existe em dois estados simultâneos e distintos: como partículas e como ondas. A partícula é um objeto físico concreto, tem massa e ocupa um espaço definido. Já a onda é invisível, não tem massa e não pode ser localizada, pode ser apenas registrada. Assim, conclui-se que o universo é sólido e invisível ao mesmo tempo. As experiências da Física Quântica têm demonstrado a coexistência partícula-onda. Esse conhecimento conjugado ao uso da realidade das ondas, possibilitou a realização das rupturas da ciência e da tecnologia, que presenciamos. Estamos percebendo o paradoxo, de podermos manipular nossa realidade física com a tecnologia, sem compreender o sentido do que fazemos.

O ponto de sintonia dessa reflexão chama a atenção, porque as redes humanas são como teias invisíveis que trançam pelo espaço, suprimindo-o, mas estão tão presentes quanto o som. Dificilmente avaliamos quão complexa é a nossa dependência do som, a teia das relações invisíveis que tecemos com ele, quer pela audição propriamente dita, quer pela conduta que nos motiva. Uma relação sólida e delicada ao mesmo tempo. Castellengo (1996) observou, objetivamente, que a capacidade de identificar rapidamente e sem erro os sons do nosso ambiente cotidiano parece natural e banal: "não percebemos tratar-se de uma conduta fundamental e complexa da qual depende nossa sobrevivência", que vai muito além do que possamos supor. A identificação dos ruídos "não foi devidamente estudada no reino do ser vivo", o que poderia contribuir, entre outras coisas, para o desenvolvimento da idéia de forma na percepção sonora.
Por isso, a proposta, neste texto, é um exercício inicial sobre as teias invisíveis do som do mundo. A intenção é chamar atenção não só para a amplitude do tema, mas para a geofonia. Uma disciplina que auxiliaria abarcar a ampla gama de fenômenos sonoros que hoje são estudados pela música, bioacústica, engenharia acústica, entre outras. A ampliação da utilização do som, aponta a necessidade de uma disciplina, que considere melhor não só a forma como percebemos auditivamente o mundo à nossa volta, mas, também, para que não ignoremos o que silenciosamente dele nos tem passado despercebido.

\section{Geofonia}

A audição, o mais primitivo dos sentidos, sede do equilíbrio e da orientação, tem sido relegada a um plano inferior. Desde a escrita mais rudimentar, à mais engenhosa máquina de visão. Portanto, audição (tempo), equilíbrio e orientação(espaço) são sentidos enfraquecidos e atrofiados no presente.

Hercules Florence, durante a expedição Langsdorff (1829) fez uma experiência de registro de "vozes" de animais, à qual denominou zoophonia. Um relato sobre essas experiências ofereceu pistas de um novo caminho para a percepção dos sons naturais. Por esse relato, o autor é considerado pai da bioacústica. No entanto, o que propunha não era tão somente uma disciplina da biologia para investigar a vocali-zação dos animais como "exibições com-portamentais", detendo-se estritamente à "função biológica dessas exibições". No estudo mais apurado do texto sobre zoo-fonia, até hoje pouco conhecido e divulgado, verifica-se que a intenção do autor foi interpretada com limitações.

Se observarmos tanto as partituras cheias de sinais, como suas indagações, fica claro que objetivava a percepção das "formas de emissão" e de como nosso ouvido imediatamente seleciona e compara os sons 
por semelhanças timbrísticas ampliando assim o repertório e o conhecimento da paisagem (ambiência), que vai se tornando familiar ou única: pela percepção da zoofonia. Florence não esboçou apenas um gesto visionário da bioacústica, ao formular timidamente a zoofonia. $O$ fato dos seus conhecimentos musicais deixarem dúvidas sobre a validade de um registro tão sutil e tão contundente como suas pinceladas, em sinais equilibrados que forjamos interpretar como "partituras", não invalidam sua intuição, ao contrário, aguça-nos os sentidos. Se admitimos que a própria escala musical varia de acordo com as culturas e que, no decorrer dos tempos, tem sido uma interpretação forjada da escala natural, podemos afirmar que pode um músico ser um músi$\mathrm{co}$, mesmo sem saber transcrever fielmente, de acordo com as normas das teorias musicais estabelecidas, um dó ou um mi. Basta que tenha ouvidos.

A intenção de Florence foi esboçar um novo campo de conhecimento, que não era o que hoje conhecemos como bioacústica, não era música e sim zoophonia, um limiar entre ambos. Uma ciência interessada em ouvir, em perscrutar e investigar as formas sonoras, como as percebemos, sem desprezar desse conhecimento a sensibilidade musical como algo inútil ou estéril.

A bioacústica, ao subtrair suas origens dos estudos de Florence, não emudece a atualidade da zoofonia como uma disciplina para o estudo dos timbres do ambiente, que nos sensibilizam. Numa era de escutar estrelas, a zoofonia de Florence salta para o futuro como geofonia.

Mesmo agora, com a tecnologia apropriada, a aproximação das ciências e da arte do som é feita com parcimônia. Como já havia percebido McLuhan(1969), decididamente não estamos numa época de ouvir, embora estejam de volta as formas de comunicação das culturas orais. Vamos acabar percebendo que mesmo os estudos sobre a poluição sonora estão ocupados com efeitos muito específicos. Mais interessados em abafar os decibéis (intensidade), ou fons nocivos (volume), ou restritos à engenharia acústica, ou mais ocupados com o registro de índices, do que com os efeitos na cidadania.

De algum modo, Florence percebeu algo que pode hoje ser investigado pelo traçado de um oscilógrafo. Suas partituras podem ser comparadas com a de músicos contemporâneos. De acordo com Castellengo, os oscilográficos que estão nos manuais de acústica, não são diretamente asso-ciáveis à percepção por duas razões. A escala temporal de representação, o período, é extremamente curto, quase não há como estabelecer relação entre milisegundos de um sinal e uma percepção. Dois sons que forneçam sensações sonoras idênticas, podem ter representações visuais extremamente diferentes. O domínio acústico, possui limitações porque depende da representação visual para fazer estudos objetivos.

A proposta de um campo de conhecimento que discuta e relacione as experiências diversas em relação ao som está aberta. A geofonia evoca não apenas o estudo de traçados de oscilógrafos, mas o estudo das nossas relações mais íntimas com o som, como elemento da música.

\section{Ambiência sonora}

Conhecer a ambiência sonora é um desafio considerável. Schafer (1991) propõe entre outras idéias interessantes a análise da soundscap (paisagem sonora). Parece estranho atribuir propriedades visuais, quando se quer observar sonoridades. Mas, numa cultura altamente visual, é mais do que comum nos referirmos a coisas ouvidas, como coisas vistas, por exemplo: ruído branco ao invés de ruído brando. A sugestão de ambiência, ao invés de paisagem, parece mais adequada, já que estamos mergulhados na atmosfera, sendo o ar um material elástico que conduz e transmite o som, formando uma ambiência que nos envolve. Em relação ao ouvido, isso é mais do que uma paisagem na qual somos apenas um ponto 
de referência. Numa ambi-ência sonora estamos envolvidos numa massa de fontes emissoras, sendo nós mesmos uma dessas fontes.

Para localizarmos melhor as mudanças de nossa ambiência sonora, carecemos de uma busca das diversas vivências, proporcionadas pela introdução de sons que cada sistema técnico tem disseminado na biosfera. Basicamente existem sons que são naturalmente produzidos, os produzidos pelo homem e os reproduzidos por seus artefatos tecnológicos. Dos sons naturais produzidos na atmosfera, temos: água, vento, chuva, etc. Sons que uma vez dispersos, nunca deixam de existir na atmosfera. São fluxos perenes, nas inúmeras dimensões acústicas proporcionadas pela topografia do terreno de cada continente, passando pelo som de insetos, ou animais (zoofonia), até chegar aos que são fomentados por cada cultura humana. Cada cidade, lugarejo, vila, cada ponto de uma estrada, floresta ou deserto tem seu timbre único, formado de centenas de milhares de outros que só a ativação de níveis diferentes de escuta, podem captar para a identificação. Se pudéssemos ver o invisível mundo das ondas sonoras, como anseia Schafer, ao propor a soundscap, perceberíamos várias imagens sobrepostas de diversos tamanhos, formas imprecisas e mutáveis perpassando umas sobre as outras, como areia movediça. Mas, aos poucos, ativaríamos algo em comum, que as tornassem mais ou menos familiares. É com essa riqueza que os sons ficam registrados no cérebro. Cada nova vivência sonora encontra ali referência única que só podemos entender melhor com o treino dos ouvidos. Por esse motivo e nesse sentido, a proposta de ouvir com atenção pode levar a redimensionar o complexo conceito de ecossistema e de biodi-versidade. Redimensionar a existência biológica e a coexistência tecnológica.

Nas aldeias e povoados, as vozes humanas se sobrepõem aos sons naturais. Estes parecem estar sob total controle da percepção humana, então capaz de discer- nir qualquer ruído ou rumor. A esse respeito Chatwin (1996), em contato com os mitos australianos da criação do mundo, nos revela as songlines. Literalmente são trilhas de canto que, percorridas por cada um dos antepassados, demarcam e revelam as fronteiras do Mar do Timor à Grande Baía Australiana. Sem se preocupar em mapear ou destacar os acidentes geográficos, panoramas ou lugares específicos, estas trilhas revelam um mundo prenhe de sentido e abundante de reminiscências. Ao reencantar versos cosmogônicos reencenam a Criação com um único apanágio : a voz humana.

Os sons pastoris foram integrando vozes humanas aos mugidos, cacarejos, balidos, piados, latidos dos animais domesticados. Outra será a ambiência sonora desenhada por arados, moinhos, monjolos introduzindo sons mais contínuos, abafando lentamente a voz humana até chegar nas máquinas a vapor. Interessante exercitar a mente nos sons de um "sistema técnico" específico, por exemplo a tríade: ferro-carvãovapor. O ferro se impondo como material dominante de construção; o carvão como combustível; e o vapor como um dos principais motores. Picon (1996) observa que a interação entre eles forma um todo coerente: "o ferro serve para construir máquinas a vapor, que permitem bombear água das minas e extrair o carvão que faz as máquinas funcionarem, servindo também à siderurgia". Neste sistema, um novo repertório sonoro é despejado na biosfera e desemboca na revolução industrial. Este novo ambiente sonoro passa a predominar como um todo coerente de sons contínuos, monótonos, fatigantes, cujos fons e decibéis expulsam gradativamente da percepção sonora: a voz humana.

Talvez para diminuir o estranha-mento, a chegada do trem a vapor tenha sido precedida pelo insistente badalar de sino, algo familiar à vida dos povoados com suas igrejas, antecedendo assim o apito ao longe, como que orquestrando a massa contínua de bufados, rangidos, guinchados e estri- 
dulados, todos combinados com o alarido dos trilhos e vagões da geringon-ça. Schafer observou que o trem tem um ruído informativo, o que não ocorre com o avião, cujo único ornamento é o efeito Doppler.

Os sinais sonoros da ampliação das primeiras linhas de comunicação começam no estalo da chicotada das carruagens chegando no meio da noites repletas de mensagens. Schopenhauer (1964) definiu como "infame", por matar a paz do sonho ou do raciocínio: o estalo do chicote tem, na mente, o mesmo efeito da chicotada no lombo do animal. Com o telégrafo, os sinais sonoros se tornam monótonos e fatigantes. Já o telefone, ao suprimir espaços, eliminou também, para melhor transmissão da voz, as freqüências mais graves e agudas, introduzindo "vozes espectrais". Aquilo que é único na voz humana ao vivo, passou a ser patéticamente semelhante para um grande número de pessoas. Isso foi uma das coisas, na época, que mais causou estranheza.

Graham Bell, antes de se tornar inventor do telefone(1856), estava envolvido com a criação do "método oral" . Professor de surdos-mudos, imaginou o telefone como imitação do tímpano. Ocupado em dar vida a esse mundo silencioso, estava imbuído em um método de ensino que abolisse a "linguagem visível" dos sinais. Bell investigou, durante anos, como a boca podia produzir tantos sons diferentes e, fazendo experiências com o diapasão, investigou com detalhes o movimento da língua. Percebeu que o som das vogais tinham uma relação com o diapasão musical. Estas pesquisas, sem dúvida, o tornaram mais do que apto à disputada descoberta. São indícios claros de que essa aptidão se deve, em grande parte, à concepção do telefone, como extensão do ouvido.

Creio que seria tarefa da geofonia o estudo mais detido de como as linhas de comunicação até as redes têm tratado o som e como modificaram o ambiente sônico no qual estamos mergulhados. Para avaliar melhor em que momento o mundo deixou de ser apenas sônico e se tornou equizofô- nico.

Seguindo os indícios do desaparecimento paulatino da voz humana, sendo abafada e lentamente substituída pela introdução de vozes sem modulação, quer pela ladainha do burburinho da massa, quer pela monotonia dos ruídos contínuos da tecnologia, surgem sinais intrigantes. De que esse desaparecimento da voz trouxe a sensação do humano fora da tecnologia e fora da própria biologia, órfão excluído de seu estar e ser no mundo.

\section{- esgoto sonoro}

Grosso modo, podemos dividir os sons em: produzidos pela natureza, animais, insetos, produzidos pelo homem e os reproduzidos por equipamentos mecânicos e elétricos, ou eletrônicos. Dentro dessa categoria, para efeito de compreensão subdividem-se entre: sons, sons musicais, ruídos e barulhos. Sons dados, produzidos e reproduzidos, que por sua vez podem ser: sutis, detalhados, agradáveis, aceitáveis, desejáveis e indesejáveis.

Por outro lado, podemos pensar na "labirintite crônica" como uma sensação de constante confusão, enredamento e turbi-lhonamento, que está ligada também ao excesso do visual e de velocidade. As grandes cidades se assemelham a jogos de videogame, com suas avenidas velozes e repletas de comandos ópticos rápidos. A "videosfera" se torna mais familiar do que a paisagem em volta, assim como se torna mais natural ouvir música reproduzida por aparelhos de som (que de "alta fidelidade" têm só o nome) do que música ao vivo, que soa cada dia mais não-natural. Há uma inversão, os sons naturais tornam-se raros e não-naturais.

Existem estudos sobre os efeitos dos decibéis excessivos, mas, pouco se têm debruçado sobre eles. Schaffer observa que "o mundo é um aeroporto", notando o perigo da "surdez perceptiva" causada por excesso de fontes emissoras. É ridícula a crença de 
que latidos de cães, ou a música artificiosa de um carro de gás incomodem mais que o estrondo dos aviões, que parecem cair sobre nossas cabeças seguidamente. A surdez perceptiva pode ser compreendida como incapacidade para separar sons produzidos de sons reproduzidos e também de ativar níveis de escuta mais finos. Trivinho(1996) observa uma diferença fundamental entre sons audíveis (produzidos), de sons auditíveis (reproduzidos), que em princípio está relacionada a níveis diferentes de escuta. Por sua vez, esses níveis diferentes de escuta dependem da nossa conduta em relação ao som, ao interesse que nos move ou desperta. Cada vez que ativamos a escuta, voluntariamente, afinamos nossa percepção em níveis diversos. Cas-tellengo observa que, quando temos uma escuta em um nível temporal mais fino, esta será mais próxima do material sonoro. Assim para mergulharmos, ou descermos a um nível de escuta fino, mais próximo da fonte emissora, necessitamos de estímulos emocionais entre outros, quando então estruturamos o sinal, segundo relações em escalas temporais diferentes. Ou seja, captamos da ambiência as suas diferenças ou minúcias, a partir da nossa motivação no momento da escuta.

Nenhuma gravação é uma reprodução exata do som vivo. Distorções são produzidas tanto na produção, como na sua reprodução. Nos equipamentos domésticos mais simples há recursos para influenciar o som, no ato de manejo do botão controlador de volume. Nos processos de mixagem de fitas, discos, CDs, os efeitos podem aumentar, duplicar até as dimensões de uma orquestra, ou diminuir ao nível do sussurro o som de um único instrumento. Nestes produtos o som já vem embalado. Grande parte dos bons aparelhos de alta fidelidade possui filtros para reduzir ou incrementar as freqüências graves ou agudas. Assim é impossível conter a seletividade, que é introduzida no ato da audição musical, e os próprios ouvintes estão aptos a controlar coisas que, no ambiente sonoro natural, estavam muito além do controle. $\mathrm{O}$ som eletrônico, ao filtrar as impurezas, perde a gama de texturas e imperfeições sonoras naturais da ambiência, causando estranheza que é, auditivamente captada como falta. Por isso Schafer propõe uma limpeza dos ouvidos e mostra a importância educa-tiva da música, por uma ecologia do som, ou, como propomos, por uma geofonia da comunicação. É necessário também, refletir numa diferença fundamental entre o barulho e o ruído.

O barulho é um som indesejável e que está sendo de algum modo produzido intencionalmente, por exemplo: o som da britadeira. Mas existem outros tipos de barulho que poderíamos identificar: o som de uma buzina é sempre intencional, no entanto o som de uma buzina é "nocivamente intencional", no engarrafamento no túnel ou na porta de um hospital. Portanto, deixa de ser um ruído aceitável e passa a ser um barulho indesejável. Outro exemplo, o som alto no rádio do vizinho é um barulho insuportável, porque está sendo produzido intencionalmente e é na grande maioria das vezes um som indesejável a qualquer hora do dia. Como o zunido da furadeira no andar de cima, às sete horas da manhã de domingo, um dia de descanso. O barulho da sirene da ambulância ou do corpo de bombeiros é sempre intencional, seus decibéis são nocivos, no entanto, pode ser classificado como aceitável, por ter uma função social. Se continuarmos a refletir, iremos notar uma série de níveis de escuta, tipos de som e seus respectivos efeitos. Não há atenção a esses detalhes em relação aos sons produzidos, ou reproduzidos, quais tipos são desejáveis, quais são indesejáveis, quais têm uma função social e quais poderiam ser atenuados ou suprimidos. Raramente, o planejamento urbano se ocupa com "esgoto sonoro" das cidades, principalmente das metrópoles.

\section{- poder do silêncio}

O silêncio não existe, é uma impossibilidade física, "sempre está acontecendo alguma coisa que produz som", afirmou 
Cage (1995) ao perceber a relatividade do silêncio. Assim, acreditou que qualquer uso da palavra, deve ser aceito como irônico, em nossos dias. Definiu música como "sons" - sons que estão à nossa volta, quer estejamos ou não dentro de uma sala de concertos. Encorajou nossa percepção na direção dos ruídos da rua, do mundo, atravessando-os e tecendo-os em suas composições. Coisa muito aborrecida de ser aceita pela grande maioria dos músicos, esse conceito despido de magia que ventila a "arte" da música como um campo aparentemente sem força. Mas qualquer definição de música no século XX, acaba sendo insuficiente para expressar ou abarcar todos os objetos e atividades que abrangem sua categoria. Música não é só o que ouvimos no rádio, o que é comandado pela mídia, o que se toca na intimidade dos lares e gostos, ou aquele som de fundo das salas de espera e nem tão somente o que está dentro da salas especiais de concertos. Se considerarmos as fronteiras do som exploradas pelas chamadas vanguardas da música atual, a propaganda, os efeitos sonoros cinematográficos, ou as diversas experiências sonoras que estão sendo produzidas em outros campos, chegaremos a muitas definições, todas parciais e insatisfatórias. Isso porque a quantidade de atividades exercidas pelos próprios músicos ampliou muito a compreensão das possibilidades do universo sonoro, conseqüentemente, do que até há pouco tempo se entendeu como universo musical.

Neste século, houve uma tremenda expansão dos instrumentos de percussão com seus sons arrítmicos e sem altura definida, gradativamente invadindo as orquestras de chiados, rangidos, atrativos... que, aliados aos procedimentos aleatórios, modificaram sensivelmente a própria forma de pensar, fazer ou perceber a música. As leis da entropia passaram a ser impor de modo irreversível. Schafer incita-nos a perceber a abertura dos "receptáculos de tempo e espaço", que são as salas convencionais de concertos, para permitir entreouvir os sons do mundo que delas se isolava. Mas se ob- servarmos os "receptáculos" dos shows ao vivo, geralmente ao ar livre, perceberemos que a amplificação audio-estéreo dos equipamentos de som é tão exorbitante, que acaba por construir uma "armadilha sonora", da qual só se pode escapar a quilômetros de distância. Não possibilita entreouvir o mundo, muito menos ouvir, porém estar dentro dele tatilmente, absorvê-lo pelos poros, não mais pelos ouvidos. O estar junto não só para fazer barulho, mas para ser parte integrante dele. Talvez como resposta sonora a um ambiente tão ruidoso e barulhento. Assim, se por um lado adquirimos uma capacidade de compreender melhor os ruídos do mundo, podendo entreouvi-los musicalmente, o barulho intencional insiste em nos capturar onde quer que estejamos, oprimindo nossa audição espontânea.

Schafer, estimula a perceber por exemplo, o que está por trás de cada peça musical - "um mundo de eventos sonoros que temos descuidadosamente aceitos como silenciosos". Mas como fomos treinados a ignorar os ruídos, costumamos ter aversão por qualquer tipo de música que nos obrigue a tecer um nível de escuta mais fino. Ficamos assim imersos na superfície dos sons. Hoje a quantidade de concertos em salas especiais é cada vez mais raro, também, a audições acústicas ao ar livre, "livres" dos equipamentos de som. Locais, enfim, onde o silêncio antes do início da apresentação tinha alguma dignidade.

O silêncio é sempre pensado em termos mais figurativos do que físicos. Atualmente a diferença do nível sonoro médio da ambiência é exorbitante, embora pouco tenhamos consciência disso. É quase impossível meditar sem o contínuo movimento da interferência sônica do telefone nos fluxos de pensamento. O pensar, sem o silêncio, possui um tecido mais curto e mais fino que um fio de seda. A partir do momento que a eletricidade acendeu suas luzes, os motores passaram a ser predominantes, como sons de baixa informação, altamente redundantes, e à medida que invadiram nossas vidas, mascararam outros sons, com o zunido oni- 
presente do progresso.

É natural que, diante de tanto barulho, fossemos inclinados a pensar no silêncio. Os supercondutores e a eletroóptica prometem trazer de volta a quietude. A eletrônica, ao contrário, está entrando em cena mais quieta. Os computadores suprimem cada vez mais o ruído, com seus componentes silenciosos. Até o teclado retirado da máquina de escrever, que teve sua origem num instrumento musical, cada vez mais suprime o estalo, por um som grave quase inaudível. As impressoras e toda a engenhoca computadorizada, carregam consigo a vantagem de serem silenciosas.

Fora do controle, ruídos e barulhos proliferam. Os sistemas clandestinos de rádio constroem uma rede de ruídos que interferem nos sistemas de navegação aérea, assim como o estampido mudo da bala perdida ameaça diretamente a segurança dos cidadãos em todo o planeta. A observação dos radiotelescópios também sofre perdas, com a interferência dos sistemas de telefonia celular. A colonização da atmosfera nos apanha, silenciosamente, com sua teia invisível •

\section{Referências}

BAYLE, François. "Ouvir e escutar" in 0 império das técnicas. Campinas, Papirus, 1996, pp.129-38.

CAGE, Jonh. De segunda a um ano. São Paulo, Huicitec, 1985.

CASTELLENGO, Michèle. "As formas sonoras" in As ciências da forma hoje. Campinas, Papirus, 1996, pp.131-41.

CATUNDA, Marta. 0 canto de Céu Aberto e de Mata Fechada. Cuiabá, Edufmt, 1994.

CHATWIN, Bruce. 0 rastro dos cantos. São Paulo, Companhia das Letras, 1996.

FLORENCE, Hercules. "Zoophonia". Rev. Inst. Histórico e Geográfico Brasileiro, tomo 39, $2^{\text {a }}$ parte, Rio de Janeiro, 1876, pp. 321-36, trad. Alfredo D'Escragnolle Taunay.

FLORENCE, Hercules. A Zoophonia. Cuiabá, Edufmt, 1993, tradução de Jacques Vielliard.

MAFFESOLI, Michel. No fundo das aparências. Petrópolis, RJ, Vozes, 1996.

MCLUHAN, Marshall. Os meios de comunicação como extensões do homem. São Paulo, Cultrix, 1969.

PICON, Antoine. "O dinamismo das técnicas" in 0 império das técnicas. Campinas, Papirus,1996, pp. 25-46.

POLLARD, Michael. Alexander Graham Bell. Rio de Janeiro, Globo, 1993.

SCHAFER, Murray. O ouvido pensante. São Paulo, Unesp,1991.

SCHOPENHAUER, Artur. "On Noise" in Studies in Pessimism, Lincoln, Nebraska: University of Nebraska, H.E. Barnes, 1964.

TRIVINHO, Eugênio. Redes: obliterações no fim de século. São Paulo, Anna Blume/Fapesp, 1998.

VENTICINQUE, E., Folwer H. \& Carvalho Jr., Martinho. "A evolução da sociabilidade entre as aranhas" in Ciência Hoje , n122, vol. 21, 32-37.

VIRILIO, Paul. "As formas virtuais" in As ciências da forma hoje. Campinas, Papirus, 1996, pp.155-64 